\title{
THE WORLD ECONOMY
}

\section{Forecast summary}

Last year the global economy expanded at its fastest pace since 201 I. We expect global growth to continue at a similar rate in 2018 and 2019.

We expect the pace of global economic expansion to slow to around 3.5 per cent a year in the medium term unless productivity growth picks up substantially.

Although some advanced economies appear to be operating at close to full capacity and oil prices have increased, our expectation is that any rise in inflation will be muted. Central banks will only raise policy interest rates gradually.

Recent announcements on tariff increases by the US and retaliations to these have added to the uncertainty about the global economic outlook. Ongoing trade talks create the potential for a rapidly changing situation which could create surprises to the global forecast outlook.

Global economic growth strengthened last year to its fastest pace since 2011 and, despite a temporary 'soft patch in the first quarter of this year in some advanced economies, we continue to expect robust annual growth over the coming year or more at around a 4 per cent pace. The 2017-19 period may, however, prove to be a mini-peak in growth as we also continue to expect the pace of growth to be around 3.5 per cent a year in the medium term.

We continue to expect annual GDP growth in China to reduce gradually, reflecting the structural changes in that economy, which, together with demographic trends generally, gives a slight downward bias to the expectation for the pace of global growth in the medium term.

As growth continues in the advanced economies and signs of labour market tightness and reduced slack gather, we expect monetary authorities to unwind policy accommodation gradually. Some withdrawal of stimulatory policy would be seen as safeguarding against potential inflationary pressures and part of a normalisation programme as output continues to expand. In line with central banks' news and market views, we do not expect sharp monetary tightening and do not see strong inflationary threats on the horizon.
The headline global GDP growth and inflation forecasts portray a continued settled economic period. However, these forecasts have important risks and uncertainties. Some of these risks could come from reduced spare capacity, possible pressures on commodity prices and upward shocks to inflation expectations. The faster pace of global output growth and lower unemployment rates in advanced economies may, in themselves, create an upside risk to the forecast from confidence effects in both economies and financial markets. Downside risks could arise from the concerns that have been expressed by some about the strong run in equities, where the shock in first quarter of the year acted as a reminder of possible volatility, and the increase in private sector indebtedness, especially at a time when policy interest rates are expected to be rising gradually.

A very important development this year has been the increase in tariffs and protectionist rhetoric from the US and the reactions of other countries. Discussions here are rapidly developing, with both threats of additional tariffs and promises of tariff reductions. Changes in a protectionist direction are a threat to world trade growth and the uncertainties around how this situation will develop are considerable.

\begin{tabular}{|c|c|c|c|c|c|c|c|c|}
\hline & \multicolumn{3}{|c|}{ World economy } & \multicolumn{5}{|c|}{ Real GDP growth in major economies } \\
\hline & $\begin{array}{l}\text { Real } \\
\text { GDP(a) }\end{array}$ & $\begin{array}{l}\text { Consumer } \\
\text { prices(b) }^{(b)}\end{array}$ & $\begin{array}{l}\text { World } \\
\text { trade(c) }\end{array}$ & US & China & Japan & Euro Area & Canada \\
\hline 2017 & 3.8 & 2.1 & 5.0 & 2.3 & 6.9 & 1.7 & 2.6 & 3.0 \\
\hline 2018 & 3.9 & 2.6 & 4.1 & 2.9 & 6.6 & 1.0 & 2.2 & 2.4 \\
\hline 2019 & 3.8 & 2.5 & 4.2 & 2.7 & 6.3 & 1.0 & 2.0 & 2.2 \\
\hline
\end{tabular}

(a) Based on global PPP shares. (b) OECD countries, private consumption deflator. (c) Volume of total world trade. 